\title{
J
}

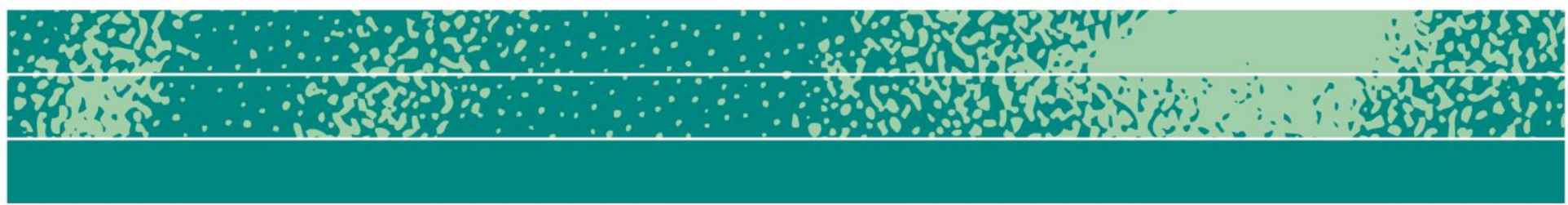

\section{Tongju Gongcai: A Case in Hong Kong's Caacaanteng}

Samuel Dic Sum Lai

'If it is not for our parents, this place would have been shut down some years ago.'

'As long as this place goes on, at the least they have a place to hang out in the afternoon. They have something to think about, go around, as a routine.'

Page 1 of 19

JBA 10(2): 283-301 Fall 2021

(C) The Author(s) 2021 ISSN 2245-4217

www.cbs.dk/jba

$10.22439 /$ jba.v10i2.6 414

\section{Carrie}

These quotations from Sai, the 'owner 'of Rainbow Café, and Carrie, his youngest sister, illustrate the importance of this business to their parents, and to their family, even though it is just a small independent eatery. Since 1966, Rainbow Café has been a community get-together place, experiencing the transformation of the city from an industrial hub to an international financial centre. It nonetheless remains a modest, almost dull establishment at a corner of an old tenement building. Sai might be the leader of this eatery in the past two decades, but his father had always 
played an important role in the business, as the respected symbolic figure, decision-maker, and rightful owner until his passing in 2020. Interviews with the family went in great depth into their family history, daily routines, and how the business intertwined with their daily lives. This study shows how an independent family business has managed to continue under the same family for generations, in a Hong Kong metropolis where individuals seek opportunities elsewhere and deem family businesses as obstacles to personal pursuits.

Family business reflects how a family operates. How a family operates in terms of hierarchy and decision-making informs the organization of the business and how the profit is allocated among the family members involved. While the Hong Kong society evolves in times of globalisation, traditional Chinese family values remain at the core of Hong Kong people's daily lives, especially for family businesses. The traditional Chinese family, jia, is a group of people defined by 'common living, common budget '( $t$ ' ung chü kung ts'ai). The family operates as if sharing a 'joint account '(Shiga 1978: 113), in which a sum of money is owned by the family but not the individuals. Traditional families operating in this way can still be witnessed among the middle age to older generations, as rare or even extinction-prone as they may be. Meanwhile, younger generations, residing with their parents given the skyrocketed housing prices, take it as their duty to provide a sum of money out of their monthly salary for their parents, adopting such a joint account notion. The joint account principle is brought into focus in this case of a family business over a 50 year period.

This family business is a historically independent Caacaanteng in Hong Kong. Caacaanteng (literal translation: tea restaurant) is a ubiquitous kind of restaurant 'conveniently located in a neighbourhood to serve ordinary customers of all ages, gender, status and occupations ... [and] serves a wide variety of food... at reasonable price' (Wu 2001: 72). One of its most well-known cuisines is the Hong Kong Style milk tea, brewed with three or more kinds of leaves and mixed with evaporated milk. Caacaanteng is further known for its efficiency in operation where one can have a dine-in meal within 15 minutes. Originating from the 1920s Bingsat (Ice room), Caacaatengs are establishments that imitate the British tea culture and serve the local Chinese population. With a century of development, while some Caacaantengs become chained eateries listed on the stock exchange, the general favourites continue to be modest independent Caacaantengs in one's own neighbourhood.

In this paper, a case study of the history, ownership, and operation of a Hong Kong Caacaanteng is showcased in hopes of broadening our understanding of the role of the family in modern Chinese family businesses. How does the Chinese family business operate? How does the joint account serve the purpose of the business, and most importantly, the family? How do Chinese family businesses continue 
thriving in this cosmopolitan Hong Kong society? How does the seemingly archaic concept of a joint account and family values continue manifesting? These are questions at the back of my head during the time I spent at Rainbow Café.

Based on my in-depth interviews with members of the family, I argue that Tongju Gongcai is still applicable to Hong Kong society, and has remained consistent over the drastic changes that took place in the $21^{\text {st }}$ century with only minor changes taking place to cope with the modern society, namely the availability of private money for the contributors to the joint account. Tongju Gongcai is not absolute in obtaining all of the money of each family member. I further argue that the traditional Chinese family values, while strict, provide flexibility in the hope of continuing the families, as demonstrated by the presence of dangjia, the family manager, subordinating to the jiazhang, the head of the family. While the roles of the two were distinct (Cohen 1976: 363), 'this arrangement allowed considerable flexibility and made it possible (at least theoretically) for the practical management of family finances (dangjia) to reside with the bestsuited man, father or son' (Watson 2004: 3). It is particularly worth noting that the appointment of a dangjia escapes the ascriptive genealogy of a family; instead of the eldest son being the necessary candidate of dangjia, the appointment of danjia is a matter of competence and not birth order. This paper sheds lights on the importance of the traditional Chinese family as both a unit and an idea, and how it informs the operation of a family business.

This paper is divided into three major sections. The first section covers Rainbow Café, the field of enquiry, and the background of Wong family, the owners of the family business. The second section chronologically delineates the organizing of work and allocation of money to family members within the original roster, when one of the family members worked elsewhere, and when that member returned. The third section discusses the concept of the traditional Chinese family based on the ethnographic data, shedding light on our understanding about Chinese family businesses in Hong Kong.

\section{Becoming a Regular and Family Friend: My Encounter with the Wong's Family}

In late February 2021, Sai, the current owner of Rainbow Café, reluctantly and regretfully posted a closure notice on the shop's front. The news shocked the neighbourhood, with old regulars returning to bid their final farewell to this time capsule of their young, innocent days. As part of my larger research into the Caacaanteng foodway in Hong Kong, I took the chance to visit the area, and asked for an interview with Sai. 
The Wong family was generally friendly and willing to help. Still, it was not common for a "young kid" with no affiliation to any local presses coming to ask for an interview. Sai politely took my name card when we met, and told me to call them some days later, passively dismissing my request. I thus turned towards my usual way of being around and turning myself into a regular: I hung around Rainbow Café consecutively for two weeks, at least an hour a day, engaging in conversations with the employees, the family members, and the regulars, and most importantly, paying for their food. They started taking me in as a kid who found much interest in their family business, which, for them, was rare. At the end, upon the recommendation of a regular customer who had read a featured article of mine in a local newspaper, Sai agreed to the interview.

However, it was clear that participant observation as an insider of Rainbow Café was impossible given their imminent closure and their tightly bonded roster. I thus relied to a great extent on interviews, especially the informal dialogues with people there. For example, while Sai was having another video interview, I reached out to his family members, namely his younger brother and sister, Bill and Carrie. I followed them wherever they were heading, asking questions ranging from the practical skills of running the store to their family stories. Now and then, they would sit down to go into details; while waiting for Sai to finish the interview, Carrie discussed at great length for two hours the family history from her kindergarten years until now. These informal conversations provided me with the information I used as a basis for the formal interviews later on and also allowed the many intricacies and hidden stories of the family to be leaked out to me.

At eight o'clock in the evening on a week day, after Sai had finished up other interviews, Sai and I finally sat down for an interview that lasted until eleven, during which he took his first meal of the day. I felt accepted by the Wong family since then, who always attended to me whenever I showed up, and updated me on various issues of my interest. They also introduced me to some of their longest regulars, one of whose family was once in the Caacaanteng business in the area. On the very last day, I was allowed to help them tidy up the place, and they even made me go to dinner with them. Beyond my expectation, they even handed me a gift, the very last paper box of Rainbow Café for their pastries back in the 70's.

My time at Rainbow Café was followed by another interview with Carrie in the hopes of seeking a third-person perspective into the fissure between the brothers, and to the family business as a daughter who had never worked there full-time. This comes together as my encounter with the Wong family and journey into the Rainbow Café.

\section{Rainbow Café: A Half-a-Century Community Hub}


Rainbow Café was established in April 1966 at San Po Kong, a district that is a ten-minute walk away from Kowloon City. In the 60's, San Po Kong was a newly founded industrial and residential area located nearby the late Kaitak airport until 1997. Workers at the airport, living around or elsewhere, formed the basic clientele for the thriving business. 'We opened at 7am. The same bus arrived every day at ten to seven and our shop was suddenly packed with passengers asking for pineapple buns. They were mostly workers at the maintenance departments' said Sai. Even with the closure of the airport, San Po Kong remains an area untouched by the Mass Transit Railway (MTR), freed from large-scale redevelopment. Not only does this area house various historical independent shops like jewelry shops or the Rainbow Café ; it is also home to the last neon sign of a bank in Hong Kong, surviving the recent wave of sign demolitions. It is common to see old couples holding their hands coming into Rainbow Café for a light afternoon tea, or hordes of middle-aged men rushing in to ask Faat his choice of horse to bet on for the upcoming race.

Rainbow Café started off as an eatery that was generally considered as a Bingsat. Just as any other early Bingsats were, Rainbow Café used to bake its own pastries, including Hong Kong-Style egg tart, Cocktail Bun and Pineapple Bun. Due to license limitations, it only sold pre-cooked simple noodle meals, namely macaroni in soup with shredded ham. Still, this menu was considered a Westernised menu and thus, given the colonial status of Hong Kong, of higher class. As time went by, and as it became a Caacaanteng in hopes of shedding its superiority and attracting a bigger clientele, Rainbow Café began to provide rice meals and even fried noodles; but because of the limited profit margin, upon the closure of the airport, they closed their bakery and bought pastries from a nearby bakery. Still, the Hong Kong-Style Milk Tea remained the same as the backbone of the drink menu.

Fifty-five years swiftly passed by, and the young bamboo shoot in the front of the shop has since grown to be the shelter for Rainbow Café, shielding it from the scorching heat of the bustling traffic exhaust and the excruciating sunshine. Although the sign reads "Rainbow," the meaning of the shop's name does not become apparent until you pass through the glass doors on the modest exterior and encounter the collage of colours waiting within. The green tables with orange booth seats line the walls, and blue tiles coat the walls with mirrors surrounding the ceiling of the shop. The floor is covered by pink and topaz tiles put in place by hand. Once seated, the waiter approaches you, wearing a white shirt embroidered with a red 'Rainbow' on the chest pocket, stained with azure from the pen he uses to takes orders. The waiter does not mind the strain, created by the countless times he stabs the pen back into his pocket. The signature black shirt is always worn only by Sai, the white vest by Bill, his youngest brother, and the chequered shirt by Man, his older brother. 
Rainbow Café housed around 52 customers at its peak, with four round tables in the middle and booths along the sides. On the right to the entrance Man usually mans the cashier; on the left is where the breads and pastries from the neighbouring shops are placed. The shop may look huge, but it is only due to its eerily small open kitchen, generally referred to as 'Bar 'in Caacaantengs. Looking straight ahead, your eyes would catch the small statue of Wong Tai Sin, a local deity, overseeing all workers and customers.

\section{The Olden Days}

Rainbow Café was run by two generations of three brothers across 55 years of business (Figure I). A blind fortune-teller, father of three and grandfather to Sai, made a fortune to start the family business. Since Rainbow's opening, he was rarely involved in the day-by-day operation of Rainbow Café and left it to his three sons.

Chen-tong Wong, born in 1927, father of Sai, was the eldest of the first three brothers in Hong Kong and the first in his family to follow his father's foot steps to come to Hong Kong by boat. He first worked at an herbal tea shop and later at a Bar in a Bingsat in Tsim Sha Tsui, one of the most vibrant business regions in Hong Kong. After settling firmly in Hong Kong, the fortune teller relocated his wife, Chen-tong's wife, and his two younger sons to Hong Kong. Chen-tong was 39 when Rainbow Café was opened and run by himself and his two brothers. Sai was ten years old, studying in primary school.

Shortly after, however, a division took place. Rainbow Café faced a drastic drop in sales with new traffic arrangements in the region, making it less accessible by residents around the community. 'Suddenly people were all gone. The region might not be all so populated after all, but it was simply deserted after sunset,' such change nonetheless left a deep impression to the young Sai then. As a result, the two uncles demanded departures from Rainbow Café. The two eventually left in 1968 and 1971, leaving Chen-tong the sole owner of the business. In 1971, Sai was at the end of his junior secondary education.

Chen-tong and his wife gave birth to 6 children in total, three daughters and three sons. While the parents and their youngest two children resided in a public housing, Man and Sai continued residing a 45min bus ride away in Kowloon City with their grandfather. When Chentong's wife was requested to help as a dishwasher, Bill and Carrie, missing their parents, sometimes slept on booth seats in order to wait for them. It was only until 1975 that they were able to all reside at a flat in the same building of the Rainbow Café.

\section{Current Family Roster}


The eldest daughter of Chen-tong was born in 1946 in Mainland China, and had already reached the age where she could work outside at the time Rainbow Café was opened. Consequently, she was never involved in any of its daily operations.

Man was born in 1956 as the eldest son. He worked at Rainbow for his whole life, initially as a waiter, and later he was mostly stationed at the cash register and made change, for which he is known for his speed in calculation and signature way of pushing the buttons on the machine. Squinting the price notes for a split second, gesturing as if there is an invisible abacus, 'clickety-clack' he presents you the change in no time.

Sai has been the person in charge of Rainbow Cafe since the early 80s. Even during his secondary study, he had already started helping out at the store. Since the 70s he started delivering take-away for the shop around the neighbourhood. By 1975, when he graduated from secondary school, he stopped his education towards the matriculation level and began waiting tables full time, and since the 80 s, he has assumed the leadership and ran the place on behalf of Chen-tong.

The second sister, just as her eldest one, was involved minimally in the operation. She did help out by giving out change when she was a child. Later she might work in the light industry as a young adult, but the family business was always more important whenever Rainbow was short-handed, she was forced to let go of her own work and came back to help, which was luckily a short-lived period for her.

Another major character in this family business is Bill. The youngest son of all has also been in the business for his whole life due to a' mistake 'early in his adulthood - he had his first daughter when he was 17, which forced him to quit his study and earn a living for his young family. First 'playing 'around at the Rainbow's bakery during his younger days, he is known for his skills in preparing the make-to-order 'hot' meals, which require more skills than drinks. Bill is particularly special for the fact that he sought out new job opportunities elsewhere in 2017. A year later, he was however asked to return in order to help Sai who could hardly manage on his own. That year, Bill left alongside his secondary school sweetheart and wife, Annie. She has been a waitress at Rainbow and has worked here since their kids reached maturity. She is dubbed the "Rainbow Mama" for her caring personality, especially towards secondary school students around the neighbourhood.

Carrie, the youngest daughter of Chen-tong, is the only daughter who is actively involved in the operation of Rainbow Cafe. While helping out at a young age, she got married and started her own pizza business. Upon the departure of Bill and Annie, and passing her pizza business to one of her employees, she worked at Rainbow Cafe as a waitress, substituting both the workload and nickname of Annie. However, in order to differentiate the two, customers tend to call her "Rainbow Auntie." 
The roster is also formed by a dishwasher, Wai, another employee at the Bar whom the family knew for a long time and returned during the year of Bill's departure, Faat, a bald waiter in his 60 s who owed his entry to the industry to Rainbow Cafe when he was a hipster with purple hair caressing his shoulders and a dragon tattoo covering his back, and Leung, a part-time waiter in the morning till two in the afternoon. Altogether, this is a small establishment run by eight at its peak and five at its downtime.

The ways of organising work and the allocation of profit under the joint account will be delineated in the following.

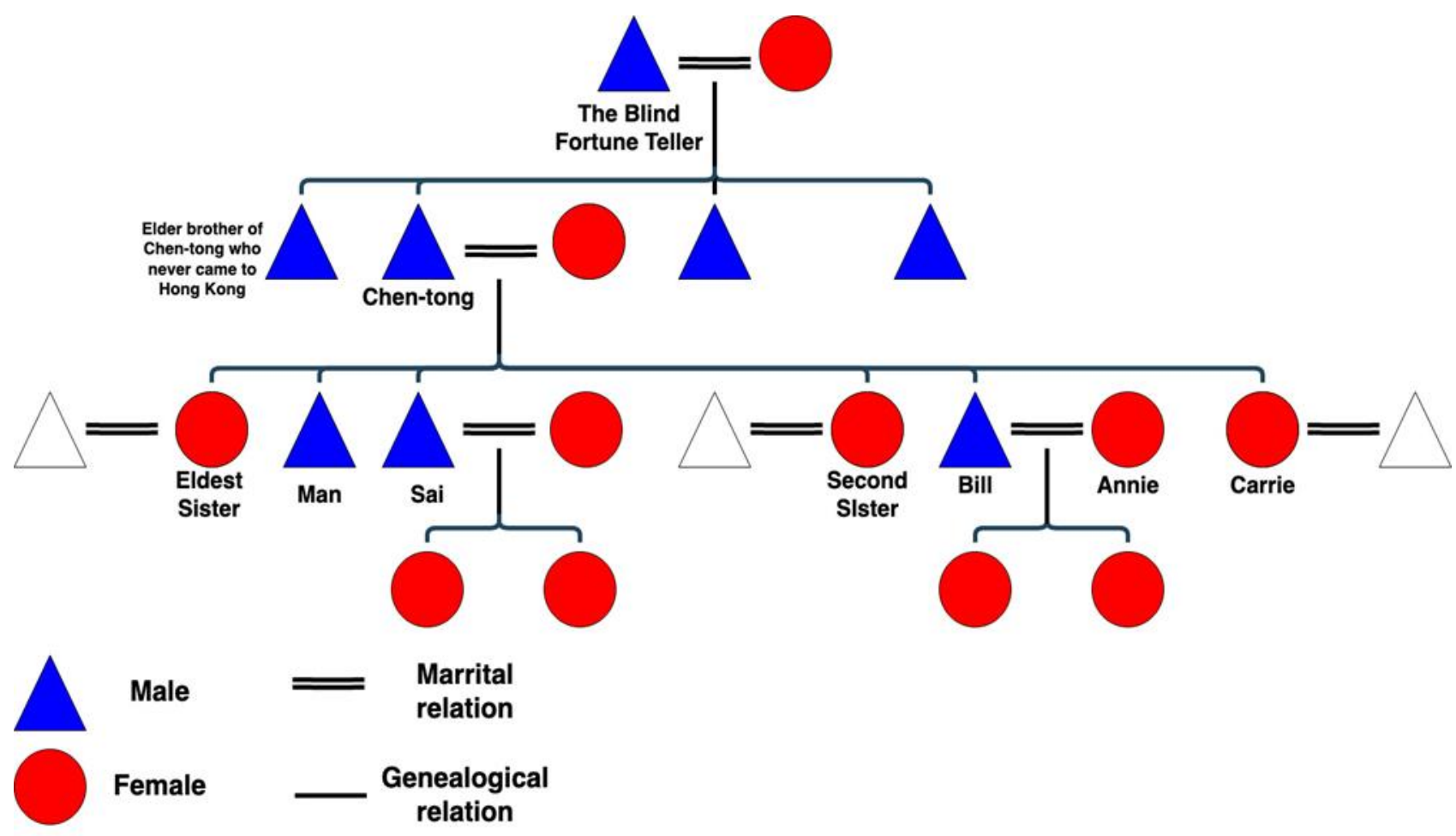

Husband outside of the family / Jia

Figure 1. The Wong Family

\section{Operation and Profit Arrangement : A Chronology}

\section{Chen-tong on-site and off-site}

'It is not a way out to work for others. That is no way to feed a family so big,' recollected Sai as the fundamental reason for the opening of Rainbow Cafe. Rainbow Cafe assumes the role of a family business and thus jiachan. While jiachan may be loosely translated as the family property, it is better understood as a productive medium for wealth (Schurmann 1956: 509), which wins the bread for the Wong family. 
Chen-tong took over the leadership of the business ever since the departure of his two brothers in 1968 and 1971, respectively. Ever since then, it serves the needs of the family of eight, which later grew in size as his children formed their own nuclear families and had children of their own.

Chen-tong, as the head of the family, took the leadership role in the family when his sons were at a young age, dictating their future as they matured. Given their limited educational level and the ready availability of a 'profession 'in the food industry, it seemed more than natural that Chen-tong would have his sons working at Rainbow. Ever since they finished their secondary school education, the elder ones, Man and Sai, never went elsewhere and worked at Rainbow as waiters. Bill, with his early marriage, not only worked at Rainbow as a waiter, but, upon the recommendation of Chen-tong, went to learn how to bake in a renowned Caacaanteng in Kowloon. All in all, Chen-tong made his three sons take up his business and prolong his family's means of production.

While all three of them began as waiters, which is more or less the easiest position in the restaurant, they assumed different positions as time went on. In most family-run Caacaantengs in Hong Kong, the founding person or owner is usually a "know-it-all", who is able to do most of the tasks, from waiting tables, making drinks, cooking cuisines, to managing the supplies of ingredients. Chen-tong was that person originally. However, with three sons taking up duties, none really came close to such a comprehensive owner.

Man, albeit being the eldest, had always been a more introverted person. While it is generally assumed that the leadership of the family business would be passed on to the eldest son, Man took a side position and mostly made change at the cashier. This has been almost his only position at Rainbow over the past decades, no matter the presence of Chen-tong at the shop or not.

By 1975, Sai, graduated from secondary school and began waiting tables full time. By the 80s, he had assumed the leadership role in the daily operations through an appointment by Chen-tong, depositing the profit to a family account under Chen-tong's name. 'I guess he saw more potential in me in terms of managing this place. I am comparatively more pragmatic and more easy-going with both employees and customers, while Bill is a bit more into his own craft and has a temper now and then,' said Sai. Every morning he wakes before half past five and arrives slightly later than six to get the stoves ready. In the morning he helps at the Bar now as they are short of cooks since the outbreak of Covid-19. By eleven, he moves to the booth to prepare ingredients for the lunch menu. He continues waiting tables until five in the afternoon when he can finally take a break and sit at the cashier, allowing Man to take off. He arrives the earliest and stays late to roll down the heavy metal gate. This has become 
his routine in the past four decades, excepting a few days during the Lunar New Year. Mostly waiting tables and preparing ingredients for different dishes, he only started taking up a position at the Bar due to Bill's departure.

Bill is the mastermind of the comparatively small Bar at Rainbow. Most of the time, it was only Bill and another cook taking up all the duties of making drinks and toasts while cooking all dishes from macaroni to make-to-order fried noodles with beef. First 'playing 'around at Rainbow's bakery at the mezzanine during his younger days, and after completing his summer baking apprenticeship, he remained at Rainbow for his whole adult life. Beginning as a waiter as well, he took advantage of a vacancy at the Bar and turned himself into a cook, claiming to be selfmastering all the skills without any help from others. Hinting that Sai is not smart enough to work at the hectic bar, he masters all the skills in the Bar, especially preparing the dishes and rice, which require more skills than making drinks.

The profit of the business is all pooled into one single account originally under the name of Chen-tong. After passing the torch to Sai in the 80s, Sai's name was also added to this account. It is recollected by Sai that for a while all four of their names are listed as the owner of this account. The profit is allocated and distributed in the manner as follows.

\section{Arrangement with and Allocation of Profit}

At the end of each month, Sai is responsible for the calculation of the profit margin of Rainbow. Repaying the debts to suppliers and salaries to employees, he also pays himself, Man, and Bill an agreed upon salary, which ranges from HKD 16,000 to 21,000. While a joint account in the traditional sense forbids the ownership of private property, the scenario here allows such ownership; after all, it is rather impossible in a modern society for a purely joint account to exist with no private money. Therefore, such salary to each of the brothers is considered private money which they need not pool into the joint account. Other earnings of their respective families, namely the salary of their wives and children, are also regarded as private money.

After covering the daily expenses of Rainbow, what remains is the actual profit. Such joint account of money would then first cover the daily necessities of Chen-tong's household, which, for the past decades, has mostly been only himself and his wife. His daily necessities include the various bills to be paid, as well as, more recently, the domestic helper taking care of the two seniors.

The profit is then used to cover the rent for the three apartments the brothers are residing in with their families. Man lives on his own in an older public housing estate, which is a smaller apartment for one person 
only; Sai and Bill reside in newer government-built housing estates, in bigger apartments for 3 or more people. It is important to note that Sai was qualified to obtain this government-built apartment with the Kwuntong family's public housing flat that they had lived in until 1975. In other words, instead of Man 'succeeding' the family house as the eldest, it was at the disposal of Sai. Given such different family sizes and needs, and the diverging housing qualities, Rainbow's profit is used to cover all their rents for the contribution of the three brothers to the business. On the one hand, their contributions are clearly different in terms of time-spent and effort: Man mainly makes change, Sai takes up the leadership role and does whatever tasks come at him, and Bill takes care of all products, the food and drinks; on the other hand, their needs from the joint account are totally different. Other than the number of children, they also keep a diverging amount of private money as a result of their disparate salaries at Rainbow, and the disparate income of their spouses. Still, they respect one another's needs and do not argue for a bigger sum as a result of their disparate contributions.

At the end, after settling all of the payment, the remaining profit is kept in the joint account until the end of the Lunar New Year. At that time, per tradition and custom of the Caacaanteng industry, a year-end profit, Paaugam (literal translation: the firework money — it is 'firework 'likely due to the auspicious time of the year to celebrate the new year), is calculated and distributed to all employees, including the three brothers.

\section{Bill's Departure}

However, the cohesiveness of the family and the joint account system was never free of challenges. In 2017, Bill refused to continue working at Rainbow and opted out of the business together with his wife, Annie. As much as mutual respect facilitated a partnership among the brothers for almost three decades, it is certain that minor disagreements built up among them, especially between the leader Sai, and Bill who has been known for his occasional temper. Even during my interview with them, their hostility towards one another could be clearly seen, as little as it might be. Bill would claim that he was smarter than Sai and thus taking care of the harder tasks at the Bar, hinting at the inability of Sai; Sai, on the other hand, whenever touching on the subject of his cooperation with Bill and Bill's departure, would resort to his ill-temper. Of course, they always came around at the end of the discussion to say that they both compromised, and how it had been about respect. But the disagreement was still clear on the surface.

When Bill departed, one may assume there would be a division in the family. This, as aforementioned, once happened to the family business back in the late 60s with the new traffic arrangement in the region. Back then, for the business, a clear-cut division took place during which Chen- 
tong's father, the original owner of the business, laid out contracts to split the properties and dividends twice for his two younger sons. While it remains unknown whether the two uncles of Sai may still contribute to the joint account of the Wong family, the division clearly took place on the business side with the contracts coming into effect.

However, regarding Bill's departure, the situation was rather ambiguous. While Chen-tong was still the head of the family at that time and the nominal leadership had long been passed on to Sai, no contract was drafted for the situation. Bill's departure took place after a long delay in the negotiation of the extension of tenancy amid the wish within the family to close the business down. 'Running your own business is really demanding. There was hardly any holiday. You basically stand on your feet the whole day. Once Bill even fainted while cooking in the middle of the day, 'said Sai, reiterating their long wish to close the business, which was also the major reason for the end of Rainbow Cafe in 2021. Coupled with the disagreement built up between Sai and Bill, Bill eventually took the bold step to leave. Bill once left Rainbow in the late 90s, although that period seemed to be of limited importance to both himself and the rest of the family, as they hardly brought it up, while the recent one seemed to really manifest a fissure between him and the others.

For eight months, Bill worked at a few different Caacaantengs but hardly worked for more than a couple of months in any of these restaurants in which he felt no ownership. 'I have been lucky to work at a place of my own. It is just different working under an actual boss whom you can only agree to. It is even worse to look at other colleagues being wasteful and not caring about their shops. Not agreeing with the boss is one thing, seeing his money being wasted is another, especially when I once ran a place, 'said Bill upon inquiring about his departure. Whether he left in the first place for freedom of his own or simply as an expression of his disagreement, the result did not seem to agree with him.

In the meantime, Bill's departure only made the operation of Rainbow harder. Rainbow Café used to have almost half of its workers directly from the family. Bill's departure brought Annie away from the daily operation. For a while, even Man took a break from work and left the business to Sai only. Sai had no choice but to hire newcomers while seeking help from old employees. 'Our shop has been notorious in terms of difficulty of work in this industry. Look at this Bar! No way you can find any other one smaller than this. Two cooks almost have to do the work of five,' said Sai when he was recollecting the difficulty he encountered in this period. To solve the issue, on the one hand, he hired new employees whom he had no experience working with, which later proved to be a huge issue with respect to the quality of their products, and on the other hand, he sought help from Carrie, his youngest sister, who had never worked full-time at Rainbow. Moreover, as a leader and waiter for the past decades, Sai had no choice but to pick up an apron, wrap it around 
his waist, and help out at the Bar, because they were short of hands, and most importantly, to make sure that the food served was up to his own standard. This ushered in an almost year-long period of difficulty during which not only did Sai work even longer hours and complete more tasks than he had previously done, but the quality of the dishes and drinks in general declined. The cost did not trickle down, but the reputation deteriorated.

However, Bill still remained in the joint account while working at other Caacaantengs. Earning a salary as an employee elsewhere, he kept the salary as his private money for his nuclear family, together with the other earnings from his wife and his children. However, even without his contribution to the joint account, the 'stipend 'to him in the form of rent remains unchanged. The rent of his household continued being covered by the profit of Rainbow Cafe just as it had been when he actually was working at Rainbow. The disagreements among the brothers did not necessarily drive Bill out of the joint account's picture. While Chen-tong continued to exert his superiority in the family hierarchy, his unchallenged role continued dictating how the joint-account money was allocated, and, most importantly, who remained beneficiaries of the account. If I were I to speculate, it appears that Chen-tong had decided not to clearly divide the family due to his understanding about his sons - the division would only be short-lived. Moreover, even if Sai disagreed with such an arrangement, given his respect for the seniority of Chen-tong, he would never go against his father's will and protest against the continuous stipend to Bill. These familial intricacies remained somewhat of a mystery.

Therefore, the departure of a family member from the family business does not necessarily end the joint account, which is the definition of a traditional Chinese family. However, one must give credit to the reverence that Chen-tong enjoyed from his children who never dared disobey his decision. The sanctity of jiazhang in this family, and his ability to bind the family together, remained absolute and unchallengeable.

In less than a year, while Bill went back to Rainbow now and then to check on how business had been, Chen-tong, seeing the hard time Sai was going through without his brothers, gave Sai a push to seek his younger brother back, and Bill kindly returned.

\section{Return of Bill}

Upon the return of Bill in 2018, Chen-tong reached the age of 92. The returning Bill enjoyed a higher salary for a cook, HKD 23,000 instead of 21,000; Rainbow was now also operated with two leaders, Sai and Bill. Without access to the company registration status of Rainbow Café, Carrie asserted that with Bill's return, he and Sai were legally the co-owners. 
Still, government registration was one thing; the family hierarchy and leadership was another. The spirit of Chen-tong prevailed in this establishment, while Sai continued being the dangjia (one in charge of the family) appointed by Chen-tong. The allocation of a stipend out of the joint account was almost identical to how it had been done before Bill's departure. The nominal joint account at the bank may be registered under both the names of Sai and Bill, but it continued serving as the real joint account of the Wong family descending from the father figure Chen-tong.

Unfortunately, Chen-tong passed away in 2020 at the age of 94 . A part of Rainbow Café might have left alongside him. But his soul continued to live in the legacy of this 54-year-old Caacaanteng. Chen-tong may not be around, but the respect for him as the late jiazhang, and the resulting cohesiveness prevails. The joint account continued existing after his death. Still, while Chen-tong used to be the head of the family, his duty, but not his role, was officially passed to the next generation now. Given the long custom of Sai playing the leading role of dangjia, the key-holder to the Wong family, is now Sai's role.

On the other hand, upon the passing of Chen-tong, the family property is passed onto the children. The dividends to Rainbow Café were evenly distributed among the three sons. As for the two estates under his name, the flat at the top floor at the back of Rainbow Café, and the last flat he resided in a zebra-crossing away, were evenly distributed among all six of his children. However, this requires further explanation in the later section concerning traditional Chinese family succession, in which the female reception of a part of the property does not necessary mean a succession from her father.

In 2021, a year after the passing of Chen-tong, Sai stuck a notice on the shop front with a pair of shivering hands, weeping and lamenting. Rainbow Café came to an end at the end of March, completing its 55 years of service to the neighbourhood of San Po Kong. 'This morning an old lady came to bid farewell to us. She used to own a salon right next to us, starting her business only a few months after us. She grabbed all our hands and thanked us. Bill went around the building afterwards to buy some supplies, bumping into her crying, 'said Sai at the night of the very last day of Rainbow Café. Rainbow Café means a lot to people around it, and to generations of students and workers at the secondary schools and airport close by. I personally felt a strong sense of regret as I looked at the sign across the street on its very last day. While Sai and Carrie joked about letting me take the business, they shared a different stance should I be their own child, noting 'even if our kids have interest in continuing Rainbow, I advise them not to do so. The restaurant industry is simply too taxing, not to mention Caacaanteng. We open almost twenty four-seven, we take no breaks. This is more of a burden than a tool for wealth for them, 'said Sai during the dinner he kindly invited me to, and in response Bill agreed with his statement with a nod and a sigh. 


\section{Discussion}

In the case of the Wong family, jia, a joint account is formed under Chentong, the jiazhang, which suggests that a jia is not defined by co-residence, but a joint account. It further demonstrates that the jia offers an organizational format for the family business: the family business is the jia, in which the jiazhang continues its symbolic leading role in its daily operation.

Jia refers to a group of people who live under 'common living, common budget '( $t$ 'ung chü kung ts'ai), understood as equivalent to a 'joint account '(Shiga 1978: 113). Shiga suggests that 'the fruits of the labor of the several members go into a common account serving all of the members without exceptions '(Shiga 1978: 112). According to Wong's paper, each jia member is required to submit all of his or her incomes to jiazhang (head of the jia) who then allocates money to jia members to cover the daily expenses according to their needs regardless of their financial contributions to the jia.

However, a pure joint account demanding all earnings of family members is improbable if not impossible, particularly in modern society where individual lives are not as much dictated by their families as before. In the current case, the sons kept their own salaries from Rainbow, while their spouses and childrens' earnings also stayed as private money for their respective household.

The three sons as components of the jia contributed to the joint account with their respective skill-sets and roles in Rainbow Café: Man making change, Sai leading the operation, Bill cooking. At the end, deducting the aforementioned salaries to the three sons (which was their private money) and settling all expenses, the accumulated surplus generated from the jia budget, in this case, Rainbow's budget, becomes family property (jia chan) (Shiga 1978: 113). This has been the common practice of Rainbow Café and the Wong family since the involvement of the three brothers in the business.

The case of the Wong family demonstrates the strict requirement for a jia, but also the flexibility a jia provides, which helps the continuation of the family and for the convenience of its daily organizing. Cohen (1976) claimed that it would be common for both jiazhang and dangjia to be the same person. However, given the old age of Chen-tong, while he is the jiazhang, Sai has been appointed the dangjia since the 80s. Dangjia, the family manager, is appointed as a matter of competence, not the order of birth. Even though Man may be the eldest, Chen-tong appointed, in his eyes, the more competent Sai to be the dangjia. Still, Man was entrusted with the important task of manning the cashier - he took charge of all flows of money towards the family business. The sweat shed may be different, but their importance is equal. 
Moreover, the dangjia of a Chinese jia does not supersede the jiazhang in authority and symbolic importance. Sai the dangjia only helped the jiazhang manage the daily organizing of the jia, and in this case, the family business as well. The sons' respect for the jiazhang ensures the perpetuation of the practice. Even without his presence, Chen-tong is here, on-site, among them. Sai the dangjia is only the extended arms of Chen-tong. Chen-tong is always the brain behind and the mastermind of the family and business. He makes all the calls on operation and profit allocation, and Sai never oversteps but only follows the wishes of Chen-tong. All in all, the dangjia appointment separates the genealogical order from the ability of individuals, allowing a pragmatic decision by the jiazhang for the daily operation of the family as well as the family business.

Taking both the jia budget and Rainbow Café itself as jia chan, which is their productive medium to generate wealth, it is important to note that such jia chan belongs to the jia but not the individuals. As Wong's paper argued, 'the qi shared between the father and the son is the genuine owner of jia-zu property and that the father and his sons as distinct corporeal forms of the same $q i$ are entitled to the property owned by qi.' As much as Chen-tong was the jiazhang, he was merely a subordinate to this jia. Sai was then further subordinate to both the jia and thus the jiazhang as the dangjia. A clear hierarchy in terms of ownership and managing rights to the jia chan is clearly demonstrated.

Besides, Bill's departure further reiterates that Tongju Gongcai does not necessarily end with the departure of a member from the business. Whether the membership of a member to a jia is removed rests with the jiazhang. The lack of a contract, and the push to have Sai asking Bill to return, demonstrates the jiazhang's authority in such matters. As long as Chen-tong wished to have Bill stay within the joint account and thus jia, no members, not even Sai the dangjia, can object. It further consolidates the position of the jiazhang.

After Chen-tong's passing, Rainbow Café continued for a year during which the joint account remained intact under the supervision of Sai the dangjia. The jiazhang might no longer be a corporeal being around Rainbow Café, but its symbolic presence continued, especially given that Sai was still only the dangjia. He did not truly became the jiazhang. It demonstrates the symbolic importance of the jiazhang even after his passing. While this may be unusual for most Chinese families, the practical integrating ability of Sai the dangjia should be applauded, allowing the continuation of the joint account, which was for the benefit of all the members. Still, with the closing of Rainbow Café in 2021, it is expected that the joint account would come to an end officially. A fenjia, a division of the jia, shall take place. The three sons, equal and independent from one another, would then officially become the jiazhang of their respective family, and it would be up to their own decisions to devise a 
joint account for their respective jia.

As for the succeeding of the jiachan, the case demonstrates the sons' entitlement to their father's family property given that they are the extension of his qi. As Wong in his paper of this special issue argues, 'jicheng ... includes three different elements: jisi, chengji, and chengye', which include the duty to take care of the old father and the obligation of worshipping the ancestors. (Shiga 1967: 113). Wong concludes that 'as a result of jisi and chengji, only sons are entitled to the family property managed by the father (chengye) (Shiga 1967: 117)'. Therefore, while the daughters received dividends to the two flats, their dividends do not necessarily mean they, lacking of the jia's qi, are 'succeeding' from the family. The daughters did not jicheng (succeed) from the family. At most we can tell that Chen-tong had been influenced by other factors and passed part of the dividends to the three daughters. But this is not a traditional practice in the Chinese jicheng (succession) system; it is only a personal choice of Chen-tong as a result of contingent reasons.

\section{Conclusion}

In this paper, I present a case of the Wong's jia and Rainbow Café, demonstrating the traditional Chinese family idea of Tongju Gongcai, of which jia is a matter of a joint financial account but not co-residence, and how the longevity of the jia rests with the decision of the jiazhang.

Furthermore, a member leaving the roster of the family business does not necessarily leave the joint account and cause a division of the jia.

I argue that Tongju Gongcai is applicable to the Hong Kong society with its adjustment in allowing the possession of one's private money, balancing the preservation of the value of family and the rise of individualism. Such system embeds in the family business and sheds light on our understanding that the family business as jia chan serves as a productive medium for wealth (Schurmann 1956: 509) for the Wong family. I further argue that traditional Chinese family values provide flexibility, with which the appointment of the dangjia is meritocratic but not genealogically ascriptive, so as to ensure the smooth practical management and continuity of the jia. Danjia of the Wong family is also the dangjia of Rainbow Café --- the family is the family business.

Rainbow Café is an ethnographic case taking place in the middle of a highly capitalistic and cosmopolitan society of Hong Kong where Chinese influence is deep-rooted and pervasive, which is particularly clear in the case of a family business. However, it is uncertain how many families continue upholding such joint accounts. As suggested by Wong in his paper of this special issue, it is particularly true that while fangs of the sons under the jiazhang jicheng (succeed) an equal amount of property from the jiazu, the fact that fangs are equal poses an arena for conflict out of fangs' self -interest and disagreement over disparate contribution to 
the jia, no matter in terms of business or contribution to the joint account in general. The joint-account notion seems to fail intrinsically under such system. It is thus worth noting of the success of the Wong's family in continuing their joint account for half a century. This rare case happened in a big family of which the 'younger 'generation has almost reached their sixties. The authority of Chen-tong, the jiazhang, and his sons' respect for him and the family institution itself are believed to be of importance to the continuation of such value. It is certain that younger generations may not agree with these values and arrangements, who are under much more individualist and influenced by capitalism. There is no doubt that another study on family business or family itself could argue that Tongju Gongcai is impossible in Hong Kong.

With the end of Rainbow Café in 2021, an interpretation of the family business from the angle of the owners can be seen. While shouldering up this family legacy for more than four decades, Sai has no doubt about the emotions he felt and memories reinvigorated upon sticking up that notice. He and his siblings grew up in this place. From sleeping on the booth seat waiting for their parents to get off from work, to meeting the uncommon European for the first time as the boyfriend of Sai's daughter, Rainbow Café means to be their whole lives. However, they still made the difficult decision to close. The closure of this family business demonstrates how the family trumps the business when the business can no longer provide. To feed a big family in 1966, the Wong family started the business as a productive medium for wealth and shieled them from the difficulties of working for others. Eventually however, to provide freedom for their children and not to make them suffer in 2021, they closed their carrier of memories. Thus, the longevity of the family trumps the longevity of the family business. This echoes with the general picture of family-run Caacaantengs in Hong Kong which fail to pass on to the next generation given the taxing nature of the industry and the ironic goodwill of the previous generation. This story of the Wong family sheds light on small independent family businesses in Hong Kong, especially for eateries, on their operation, continuity and future.

\section{References}

Chen, Chi-nan. 1986. "Fang and Chia-tsu: The Chinese Kinship System in Rural Taiwan." PhD dissertation, Department of Anthropology, Yale University.

Chun, Allen. 1985. "Land is to Live: A Study of the Concept of Tsu in a Hakka Chinese Village, New Territories, Hong Kong.” PhD dissertation, Department of Anthropology, The University of Chicago.

Cohen, Myron. 1976. House United, House United. New York: Columbia 
University Press, pp. 363.

Lai, Samuel Dic Sum. 2020. "Food and the Hong Kong Imaginary: The Gold Garden Café.' MA dissertation, Department of Anthropology, Goldsmiths, University of London.

Schurmann, H. Franz. 1956. "Traditional Property Concepts in China." The Far Eastern Quarterly 15(4): 507-516.

Shiga, Shūzō. 1978. "Family Property and the Law of Inheritance in Traditional China" in Chinese Family Law and Social Change: In Historical and Comparative Perspective, edited by David C. Buxbaum. Seattle: University of Washington Press, 109-150.

Watson, Rubie. 2004. 'Families in China: Ties that Bind?'. "The Family Model in Chinese Art and Culture" Conference Volume. Princeton University: Tang Centre for Asian Art. November 6-7, 2004.

Wu, David Y. H. 2001. 'Chinese Cafe in Hong Kong'. In Wu, David Y. H. \& Tan, Chee-Being. 2001. Changing Chinese Foodways in Asia. Hong Kong: The Chinese University Press.

Samuel Dic Sum Lai obtained his MA in Social Anthropology at Goldsmiths, University of London, and is currently a teaching assistant at the University of Hong Kong. His research interests include anthropology of food, business anthropology, Hong Kong food culture, as well as organizational behaviour. 